\title{
Criatividade e perspectivas globais: entre definiçóes clássicas e contemporâneas
}

\author{
Rejane Gomes Tavares ${ }^{1}$ \\ https://orcid.org/0000-0002-7226-8749 \\ Marilza Vanessa Rosa Suanno ${ }^{2}$ \\ https://orcid.org/0000-0001-5892-1484
}

\section{Resumo}

O presente artigo apresenta resultados parciais de pesquisa em desenvolvimento vinculada à Programa de Pós-Graduação em Educação que discute definiçôes e aspectos globais vinculados a criatividade. Explorar tal temática tem exigido um esforço de organização e articulação conceitual considerando a complexidade do termo. Assim, este estudo visa estabelecer relaçôes entre concepçōes de criatividade a partir de cinco perspectivas globais, quais sejam: a) processo; b) produto; c) condição/ambiente; d) pessoa/personalidade; e) integração (MITJÁNS MARTÍNEZ, 1997). Para tanto, foram analisadas definiçôes compiladas por Torre (2008), bem como nas pesquisas de Suanno (2013) e Ribeiro e Moraes (2014). Metodologicamente foram analisadas 44 definiçōes de criatividade, as quais aproximadamente $51 \%$ focaram em uma das perspectivas globais listadas acima, e 49\% contam com a integração de dois ou mais aspectos. Destes, constatou-se que $41 \%$ das definições trazem características que remetem a pessoa/personalidade. Conclui-se que o conceito de criatividade demanda pesquisa e explicitação da relação entre concepções e elaboraçóes conceituais, assim como sinaliza para a necessidade de aprofundamento da perspectiva integradora e complexa de criatividade.

Palavras-chave: Educação, Criatividade, Perspectivas globais.

1 Mestranda do Programa de Pós-Graduação em Educação (PPGE) da Faculdade de Educação (FE) da Universidade Federal de Goiás (UFG), tendo como orientadora a Profa. Dra. Marilza Vanessa Rosa Suanno. Bolsista CAPESEdital PPGE/FE/UFG No 02/2020. Membro do Grupo de Estudos e Pesquisas em Didática e Questóes Contemporâneas - DIDAKTIKÉ (FE/UFG). E-mail: rejane.gt@hotmail.com.

2 Doutora em Educaçáo pela Universidade Católica de Brasília - UCB (2015). Doutorado sanduíche realizado na Universidade de Barcelona - UB (2011/2012). Líder do DIDAKTIKÉ - Grupo de Estudos e Pesquisas em Didática e Questóes Contemporâneas http://dgp.cnpq.br/dgp/espelhogrupo/7805627761585698 DGP/CNPq. Membro dos Grupos de Pesquisa: a) Ecologia dos Saberes e Transdisciplinaridade Ecotransd/UCB; b) Rede Internacional Investigando Escolas Criativas e Inovadoras - UFT; c) Rede Internacional de Escolas Criativas: construindo a escola do século XXI - RIEC (UB/Espanha) e d) Pesquisas e Práticas de Aprendizagem Integradora e Inovadora - PAII/UFAL. Membro do Núcleo de Formaçáo de Professores da Faculdade de Educaçáo - FE/UFG. Membro da Asociación de EscuelasCreativas- ADEC (Barcelona/ES). E-mail: marilzasuanno@uol.com.br. 


\title{
Global creativity and perspectives: between classic and contemporary definitions
}

\begin{abstract}
This article presents partial results of research in development linked to the Postgraduate Program in Education that discusses definitions and global aspects linked to creativity. Exploring this theme has required an effort of organization and conceptual articulation considering the complexity of the term. Thus, this study aims to establish relationships between conceptions of creativity from five global perspectives, namely: a) process; b) product; c) condition / environment; d) person / personality; e) integration (MITJÁNS MARTÍNEZ, 1997). To this end, definitions compiled by Torre and Viollant (2008) were analyzed, as well as in the research by Suanno (2013) and Ribeiro and Moraes (2014). Methodologically, 44 definitions of creativity were analyzed, which approximately $51 \%$ focused on one of the global perspectives listed above, and $49 \%$ rely on the integration of two or more aspects. Of these, it was found that $41 \%$ of the definitions bring characteristics that refer to the person / personality. It is concluded that the concept of creativity demands research and explanation of the relationship between conceptions and conceptual elaborations, as well as signaling the need to deepen the integrative and complex perspective of creativity.
\end{abstract}

Keywords: Education, Creativity, Global perspectives.

\section{Introduçáo}

Criatividade, etimologicamente, tem sua raiz no latim creare que se refere a formar, produzir e criar. Em dicionários da língua portuguesa nos deparamos com a definição de criatividade como uma qualidade de uma pessoa que seja criativa, sendo esta detentora de capacidade, inteligência e talento para criar, inventar ou fazer inovações na área em que atua; além disso, a indicam como originalidade.

No entanto, ao analisar os conceitos atribuídos a criatividade nos deparamos com uma imensa quantidade de definiçóes, algumas se assemelham em certos pontos, e outras, se distanciam quanto aos aspectos propostos pelos pesquisadores e pesquisadoras que a definem.

Criatividade é um conceito pesquisado por diversas áreas do conhecimento e estas apresentam distintas definiçôes de criatividade, seja dado o objeto especifico da área, seja pela abordagem epistemológica, de tal modo é possível identificar aproximaçóes e distanciamentos entre tais perspectivas. Por conseguinte, não há um consenso para definição de criatividade.

Independente da área do conhecimento, considerando a diversidade conceitual clássica e contemporânea de criatividade, Mitjáns Martínez (1997) 
propóe a classificação e reflexão em torno de cinco perspectivas globais em torno do conceito de criatividade, quais sejam: 1) processo; 2) produto; 3) condições; 4) pessoa; e 5) integração.

Partirmos do pressuposto de que a criatividade é algo que se aprender, que se desenvolve e se aprimora. Por conseguinte, a criatividade não é um dom ou algo nato, mas algo que precisa ser trabalhado para ser desenvolvido, algo que pode ser aprendido e para tal demanda oportunidades, condiçóes e vivências, bem como ambientes que sejam propícios, desafiadores e desestabilizadores, que estimule a imaginação e a atitude criadora, que contemple dimensões contextuais, culturais e estéticas, dentre outros inúmeros fatores (PRADO DÍEZ, 2006).

Enfim, a criatividade é algo passível de aprendizado e desenvolvimento e demanda de oportunidades nos diversos contextos e ambientes, sejam escolares, estéticos, familiares, profissionais, dentre outros.

Para a construção do presente artigo metodologicamente realizamos uma pesquisa qualitativa na busca por organizar e refletir sobre concepçóes clássicas e contemporâneas de criatividade considerando as cinco perspectivas globais (MITJÁNS MARTÍNEZ, 1997).

Desta forma, na sequência explicitaremos a metodologia utilizada na pesquisa e, em seguida, apresentamos um diálogo com pesquisadores e pesquisadoras acerca do conceito de criatividade, para entáo apresentarmos uma análise de concepçóes clássicas e contemporâneas.

\section{Metodologia}

Esta pesquisa de abordagem qualitativa buscou analisar concepçóes de criatividade oriundas das décadas de 1950 a 2010, relacioná-las as perspectivas globais (produto, processo, condição/ambiente, pessoa/personalidade e integração) e pensá-las de forma complexa.

Para isso, inicialmente foram identificadas 44 (quarenta e quatro) concepçôes de criatividade em Torre (2008), Suanno (2013) e Ribeiro e Moraes (2014). A escolha de Torre (2008), bem como do referencial teórico que dialoga com cada uma das perspectivas globais teve por base publicaçóes desse pesquisador devido este ser um professor emérito da Universidade de Barcelona que se dedicou a pesquisas acerca da criatividade em toda a sua trajetória profissional, se tornando um propulsor de redes, associaçóes, congressos e outros considerando a temática da criatividade e que reuniu em 
suas produçóes autores clássicos e contemporâneos que são referência no estudo da criatividade.

No esforço por classificar as perspectivas da criatividade foi elaborado um quadro contendo as cinco perspectivas globais e aspectos inerentes as definiçóes em estudo. A distribuição das definiçôes no quadro favoreceu que, em seguida, fosse realizada uma análise identificando similaridades e distanciamentos entre as características apresentadas, bem como uma visualização em percentual quanto a frequência do enfoque contemplado. Por fim, tendo por base os princípios do pensamento complexo (MORIN, 1999 e 2004; MORIN; CIURANA; MOTTA, 2007) buscou-se construir algumas articulações conceituais.

\section{Cinco perspectivas globais no estudo da criatividade}

Considerando as cinco perspectivas globais dos estudos sobre criatividade (processo, produto, condição/ambiente, pessoa/personalidade e integração) passamos a abordar cada uma destas na sequência.

A primeira perspectiva foca no processo criativo e conforme Mitjáns Martínez (1997, p. 10) esta "inclui os trabalhos que procuram descrever e explicar como ocorrem os processos criativos e os outros que nele intervêm". Para Alencar (2006) os estudos sobre o processo criativo têm abordado diferentes aspectos, como: os processos cognitivos, o estudo do processo criativo específico de um indivíduo e a dimensão social em que o processo criativo ocorre.

O supracitado autor apresenta distintas fases do processo de criação mostrados por Poincaré: $1^{\mathrm{a}}$ - fase reflexiva de investigação e de cálculo; $2^{\mathrm{a}}$ fase inconsciente de maduração de ideias; $3^{a}$ - fase de verificação de ideias. Aborda também as fases apresentadas por Helmholtz (1974): $1^{\text {a }}$ - saturação reunião de informaçóes que contribuem com o surgimento de novas ideias; $2^{\mathrm{a}}$ - incubação - quando há uma combinação de novas ideias sem esforço consciente; $3^{\text {a }}$ - iluminação - o surgimento de uma nova solução ou resposta. Além disso, traz os estágios apresentados por Wallas (1926, 1979): $1^{\text {o }}$ preparação - investigação do problema; 2o - incubação - ocorrem acontecimentos mentais involuntários, uma vez que o indivíduo não está conscientemente pensando no problema; $3^{\circ}$ - iluminação - o insight ocorre de maneira inesperada; $4^{\circ}$ - verificação - avaliação da ideia proposta de caráter crítico podendo resultar em reformulação. Assim, o primeiro e último momento são marcados por interaçóes, problematizaçóes, mediaçóes e 
reflexôes. Considerando o exposto, Stein (1974) propôs que acrescentasse a etapa de elaboração de hipóteses e Stein (1974), Motamedi (1928) e Amabile (1996) ressaltaram a necessidade de comunicação dos resultados, o que acarretaria uma nova etapa marcada pela validação.

Durante o processo criativo é preciso saber buscar e usar as informações, uma vez que estas seleçóes são marcadas por afetos e valores pessoais (ALENCAR, 2006 apud VASS; MEANS, 1989), bem como por conhecimentos, saberes e sensibilidades.

De acordo com Alencar, Neves-Pereira, Ribeiro e Brandão (1997) distintos momentos do processo criativo podem ser influenciados por atributos pessoais tais como: abertura a novas ideias; atitude de observação; envolvimento e gosto pela realização da atividade; conhecimento acerca do campo proposto; entusiasmo, dentre outros.

Os estágios do processo criativo não dependem somente de fatores intrínsecos, eles também dependem de condiçôes ambientais, sociais e culturais. Interaçóes sociais podem propiciar insights a partir de diálogos, debates, vivências, leituras coletivas dentre outros. Assim, Alencar (2006) reforça que, de acordo com Montuori e Puser (1995), não se trata de um fenômeno exclusivamente intrapsíquico, mas que considera forças políticas e sociais. Dessa forma Alencar (2006) nos traz por meio de Arieti que, no processo criativo, o papel da sociedade se dá a partir de diferentes fatores como: a disposição de meios culturais, abertura a estímulos ambientais, o acesso aos meios culturais, a exposição a estímulos e oportunidades diversificadas, além da presença de editais, incentivos e prêmios.

Para Montuori e Purser (1995) e Heller (1991) a liberdade de poder trabalhar em áreas de interesse pessoal, o reconhecimento e o estímulo por parte de companheiros influenciam positivamente no processo criativo. Alencar (2006) destaca também, se apoiando em Stein (2003), que o apoio financeiro, emocional e o feedback são importantes no processo criativo por proporcionarem condiçóes necessárias para dedicação à criação. Isso, sem se esquecer da relevância de avaliadores que conferirão credibilidade ao resultado.

Portanto, o processo criativo, segundo Alencar (2006) necessariamente não se constitui em uma sequência linear; considera a conjunção de aspectos cognitivos, afetivos e sociais; se faz indispensável o domínio do conhecimento da área específica em questão; é necessário a utilização de estratégias metacognitivas; a disponibilidade de tempo e recursos ampliam as possibilidades. 
A segunda perspectiva global no estudo da criatividade foca no 'produto' e nas atribuiçôes e características a obra final resultante da criação. Nesse sentido, Mitjáns Martínez (1997) apresenta que autores de tal perspectiva abordam a criatividade considerando a especificação das características do produto 'criativo'. De acordo com Menchén Bellón (2006) existem critérios para categorizar um produto criativo, tais como: a) ser novo e valioso para todos; não ser convencional; ser resultante de motivação e persistência e resultado de um problema prévio (NEWELL; SHAW; SIMON, 1958 apud MENCHÉN BELLÓN, 2006); b) novidade; quantidade; generalização; compreensão (BRODGEN; SPRECHER, 1964 apud MENCHÉN BELLÓN, 2006); c) possuir reconhecimento social por uma comunidade (CSIKSZENTMIHALYI, 1998) e d) ter uma aceitação final (AMABILE, 1996 apud MENCHÉN BELLÓN, 2006).

Para Mitjáns Martínez (1997, p. 10) ao focar nas 'condições/ambiente' a terceira perspectiva global nos estudos da criatividade "inclui os trabalhos que tentam explorar as situaçóes ou condiçóes que possibilitam ou não a atividade criativa. Entre esses estudos se destacam os que têm por objetivo a análise dos vínculos e da grupalidade, e sua influência na atividade criativa”.

González Quintián (2006) ao refletir sobre as condiçóes e o ambiente propiciador da criatividade destaca que para D. Parkins os ambientes são cenários de interação e para Vigotski o meio oferta experiências, interesses, necessidades, assim, a criatividade ocorre proporcionalmente a tais oportunidades. Para Arieti (1979) um clima propício a criatividade é fruto de influências, aspectos e acesso a bens socioculturais. Já Sternberg (1996) o processo criativo deve ter ambiente provocador e enriquecido. Csikszentmihalyi (1996) por sua vez argumenta que é possível criar ambientes que sejam propícios a criatividade. E Torre (2003) realça que o ambiente influencia e é influenciado por meio de aspectos naturais, culturais e sociais, que são cenários com valor pedagógico.

Segundo Morejón (2006) existem condiçóes que influenciam na inserção da criatividade no ambiente escolar, tais como: o clima, o lúdico, a mediação do educador, dentre outros. O clima ou atmosfera criativa trata-se de um fenômeno psicossocial que é complexo, pois pode influenciar ao tentar propiciar um ambiente criativo. Morejón (2006) ao analisar a temática e fundamentar-se em Betancourt (2004) e Vigotsky (1979) faz referência a alguns aspectos no que se refere ao ambiente criativo considerando que estes devem promover: a relaçáo da pessoa com o meio; o estímulo de competências e saberes que se dão de maneira mediada pela história e cultura dos estudantes; a pessoa criativa como sendo inteligente; favorecer a união entre os afetos e o 
intelecto; valorizar tanto o produto quanto o processo criativo; dar sentido ao erro; favorecer valores humanos e estimular uma motivação intrínseca.

O lúdico, de acordo com Morejón (2006), é indispensável para propiciar um ambiente criativo e embasando-se em Betancourt (1992) defende que o lúdico e o jogo devem ser incorporados na sala de aula.

Para Morejón (2006) baseado em Torrance (1976) e Lipman, Sharp e Oscanyan (1996) um ambiente criativo, especialmente em instituições escolares, deveria ter um mediador capaz de favorecer um clima capaz de impulsionar a criatividade, neste sentido parece importante que o mediador: demonstre interesse em distintos pontos de vista; estimule o diálogo mais que o encontro de respostas; crie uma dinâmica de ajuda mútua, colaboração e partilha ente os estudantes; estimule o respeito por cada ponto de vista; proporcione o desenvolvimento de opiniôes e capacidade de argumentação; mantenha o clima de construção do conhecimento; estimule a participaçáo; estimule decisóes criativas e inteligentes; busque atividades que tenham resoluçóes abertas e plurais; identifique ocasióes apropriadas para questionamentos reflexivos; aproveite as oportunidades para a exploraçáo de novas visóes, bem como, favoreça a problematização e a indagações sobre as ideias expressas; amplie o repertório de questionamentos e buscas; respeite o tempo de cada atividade; busque outras versóes para os temas; amplie e diversifique as formas e os conteúdos em estudo e articulação; acompanhe o desenvolvimento dos estudantes; respeite os distintos estilos e ritmos de aprendizagem (MOREJÓN, 2006).

Morejón (2006) destaca também que há outros fatores indispensáveis para proporcionar uma atmosfera criativa, sendo elas: a) as condições materiais; b) a promoção do humor; c) estimulação da cooperação; d) encontro combinatório e divergente; e) relação figurativa e transformadora; f) espaço de potencial e transformação; g) comunicação; h) estar aberto e flexível.

A quarta perspectiva global nos estudos da criatividade focam na 'pessoa' e ou na 'personalidade', bem como nos processos pessoais e psicológicos que interferem na atitude criativa, ou seja, tal perspectiva "inclui os trabalhos dirigidos a revelar as qualidades, características, elementos ou processos psicológicos subjacentes, que possibilitam a criatividade" (MITJÁNS MARTÍNEZ, 1997, p. 10).

A pessoa se constitui em um ator principal da criação devido ao fato de ser observador, ser detentor de opção de escolha, ter possibilidade de tomadas de decisóes, ser capaz de identificar distintas probabilidades e complexidades. A criação, para Rosman (2006), tem caráter atemporal, por uma 
impossibilidade de definição do começo e do fim. Assim, ao surgir uma criação nasce também um espaço, um tempo e a própria criação.

Para o supracitado autor, a criatividade e a pessoa criativa não se separam, pois se trata de incógnitas que não podem ser reduzidas facilmente a uma lista de características. Enumerar características a uma pessoa criativa seria um risco ao tentar abarcar uma ideia complexa em poucos traços. Seria uma redução. No entanto, Rosman (2006) se baseia em Torre (1982) para afirmar que o centro da compreensão do enfoque na pessoa criativa está na personalidade criativa e nas características da pessoa criativa, assim atribuídas por diferentes pesquisadores da área, ou seja por: a) Torrance - como enamorada, corajosa, independente de pensamento e juízo, honesta, perseverante, curiosa, com vontade de correr riscos, etc.; b) Maslow (1983) como uma pessoa que está imersa nas situaçôes presente, que não se perde com o passado ou o futuro; c) Rodríguez (2001) - como uma pessoa que nunca está completamente realizada, que se vai realizando; Amabile (1996) - que as pessoas criativas são inconformadas, são fortes mentalmente $\mathrm{e}$ emocionalmente, que tem um desejo constante de fazer algo e deixá-lo como contribuição.

A criatividade e a pessoa criativa, em sua essência, unidades ou totalidades. Separá-las seria fragmentar, uma vez que a pessoa é tão ou mais complexa que o próprio processo criativo (TORRE, 1997 apud ROSMAN, 2006).

Rosman (2006) ainda apresenta que há criações com “c” minúscula e outras com "C" maiúscula, porém não há como equiparar as genialidades de pessoas, cada uma é constituída por possuir características que lhe são peculiares e únicas.

Assim, Rosman (2006) concorda com Amabile (1989) de que todos somos criativos e que a manifestaremos conforme as possibilidades e as condiçôes. Todo ser humano é capaz de produzir algo criativo em algum momento em alguma área. Portanto, a criatividade não é exclusiva de superdotados, ou seja, de alguns. Rosman (2006) ao resgatar Stenberg e Lubart (1997) afirma que cada um é criativo em certa medida. Ainda acrescenta que, apoiado em Rodríguez (2001) náo podemos deixar de ser criativos, temos que assumi-la e não a abandonar. Se a deixamos de lado, estaremos nos abdicando de parte de nosso ser pessoa.

A criatividade acontece na interaçáo das pessoas com um contexto sociocultural, se constituindo em um fenômeno sistêmico (CSIKSZENTMIHALYI, 1996 apud ROSMAN, 2006). 
$\mathrm{Na}$ quinta perspectiva global nos estudos da criatividade foca na 'integração', que segundo Mitjáns Martínez (1997, p. 10) “inclui os trabalhos que não sublinham um ou outro elemento, mas procuram explicar a criatividade em função da integração ou conjunção de mais de um desses elementos (geralmente o sujeito e as condiçóes)". Assim, entendemos como sendo a articulação de uma ou mais perspectivas globais no estudo da criatividade. Interessa-nos que se ampliem pesquisas e projetos com foco na integração dos aspectos $\mathrm{da}$ criatividade, pois há potencialidade e potencialidades por explorar.

\section{Definiçóes clássicas e contemporâneas de criatividade a luz das cinco perspectivas globais}

Almejamos analisar concepçóes consideradas clássicas e contemporâneas de criatividade que foram compiladas por Torre (2008) e outras extraídas das pesquisas de Suanno (2013) e Ribeiro \& Moraes (2014), tendo totalizado 44 (quarenta e quatro) definiçóes dos autores e autoras, a saber de: Aznar (1974); Barron (1973); De Bono (1986); Dudek (1993); Fernández Huerta (1968); Freud (1958); Fromm (1982); Gervilha (1986); Guilford (1977); Gutman (1967); Marín Ibáñez (1980); May (1979); Mednick (1980); Murray (1982); Osborn (1971); Parnes (1962); Prado Díez (1986, 1999); Rogers (1959); Sillamy (1973); Stein (1967); Thurstone (1968); Torrance (1966); Torre (2003, 2008); Alencar e Flith (2003); Benning (1996); Csikszentmihalyi (1998); Stenberg (1976); Betancourt (1992, 1993); Dabdoub (2005); González Quintián (2006); Herrán Gascón (2003); Menchen (1991, 2011, 2012); Mitjáns Martínez (1997); Moraes (2006); Motos (1990); Rosman (2006); Suanno (2013); Amabile (1985); Kaufman (2006); Tindó (2009); Runco (1996, 2007); Weschler (2011); Brunner (2008); Dittrich (2010).

Ao analisamos as definiçóes no que se refere a perspectiva de criatividade assumida identificamos uma maior incidência na criatividade centrada no estudo da pessoa criativa, da personalidade criativa, conforme podemos observar no gráfico 1 : 
Gráfico 1: Distribuição das definiçóes conforme perspectiva abordada

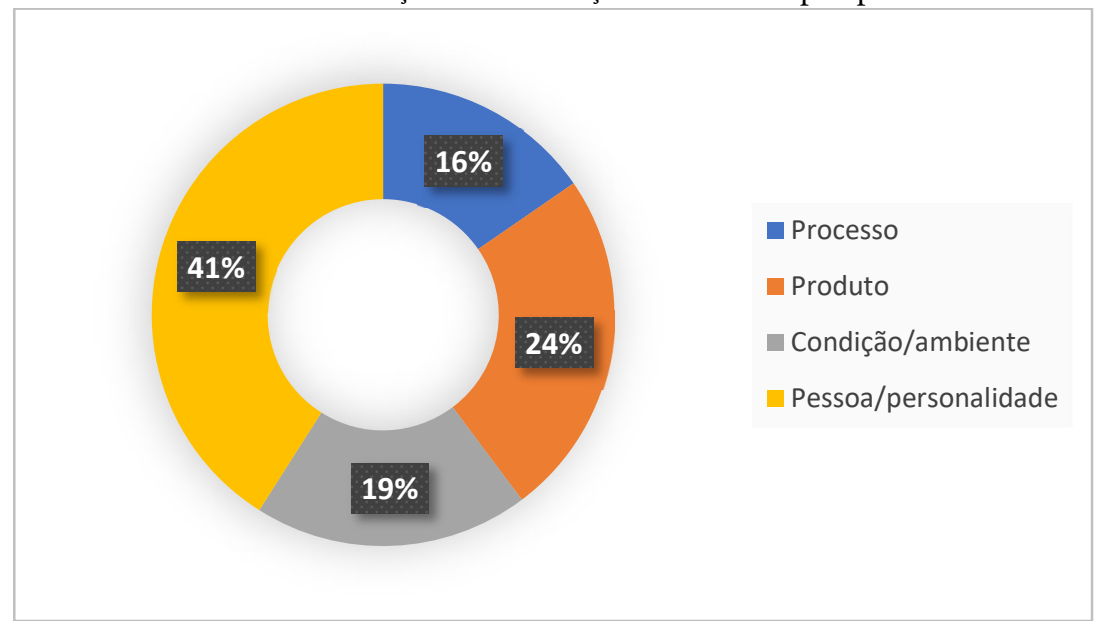

Fonte: Tavares e Suanno, 2020.

Como demonstrado no gráfico 1 um porcentual próximo de $16 \%$ das definiçóes trouxeram aspectos referentes a ideia de processo criativo; em torno de $19 \%$ com aspectos característicos que remetem a condição/ambiente criativo; aproximadamente $24 \%$ das definiçóes trataram do produto criativo; e por volta de $41 \%$, a maioria, apresentaram ideias que se referenciam a pessoa/personalidade criativa.

No quadro 1 encontramos a distribuição dos pesquisadores e pesquisadoras conforme a perspectiva apresentada na definição de criatividade analisada.

Quadro 1: Distribuição de pesquisadores conforme o enfoque de sua concepçáo

\begin{tabular}{|l|l|}
\hline Enfoque & Autores \\
\hline \multirow{5}{*}{ Processo } & Medinick (1980); Benning (1996); Torrance (1966); \\
& Murray (1982); Thurstone (1968); Suanno (2013); Stein \\
& (1967); Dabdoub (2005); González Quintián (2006); Torre \\
& (2003, 2008); Marín Ibánez (1980) \\
\hline \multirow{5}{*}{ Produto } & Gutman (1967); Moraes (2006); Murray (1982); Thrustone \\
& (1968); Barron (1973); Gervilha (1986); Prado Díez (1986, \\
& 1999); Osborn (1971); Parnes (1962); Fernández Huerta \\
& (1968); Guildord (1977); Stein (1967); Dabdoub (2005); \\
& Rogers (1959); Brunner (2008); Csikszentmihalyi (1998); \\
& González Quintián (2006); Torre (2003, 2008); Marín \\
& Ibánez (1980) \\
\hline \multirow{2}{*}{ Condição/ambiente } & $\begin{array}{l}\text { Alencar e Flith (2003); Motos (1990); Suanno (2013); May } \\
\text { (1979); Amabile (1985); Betancourt (1992, 1993); }\end{array}$ \\
\hline
\end{tabular}




\begin{tabular}{|l|l|}
\hline & $\begin{array}{l}\text { Weschler (2011); Stein (1967); Dabdoub (2005); Rogers } \\
\text { (1959); Brunner (2008); Csikszentmihalyi (1998); González } \\
\text { Quintián (2006); Torre (2003, 2008); Marín Ibánez (1980) }\end{array}$ \\
\hline \multirow{5}{*}{ Pessoa/personalidade } & Aznar (1974); De Bono (1986); Dudek (1993); Freud \\
& (1958); Fromm (1982); Sillamy (1973); Runco (1996, \\
& 2007); Stenberg (1976); Rosman (2006); Mechen (1991, \\
& 2011, 2012); Dittrich (2010); Kaufman (2006); Herrán \\
& Gascón (2003); Tindó (2009); Mitjáns Martinez (1997); \\
& Barron (1973); Gervilha (1986); Prado Díez (1986, 1999); \\
& Osborn (1971); Parnes (1962); Fernandez Huerta (1968); \\
& Guildord (1977); May (1979); Amabile (1985); Betancourt \\
& (1992, 1993); Weschler (2011); Rogers (1959); Brunner \\
& (2008); Csikszentmihalyi (1998); González Quintián \\
& (2006); Torre (2003, 2008); Marín Ibanéz (1980) \\
\hline
\end{tabular}

Fonte: Tavares e Suanno, 2020.

Para Alencar (2006) o processo criativo é constituído de etapas que conduzem a um resultado, com intencionalidades claras e processos espontâneos, contendo etapas não necessariamente pré-estabelecidas, uma vez que o processo criativo não é linear ou sequencial, ou seja, não é constituído por fases rígidas podendo ocorrer de distintas maneiras e por meio de variadas vivências e técnicas que planejadas conduzirão a um resultado final, a partir de processo de reflexão, investigação, produção, verificação e comunicação.

A definição de processo criativo para os autores citados no Quadro 1 caracteriza-se por etapas como: formação de combinaçóes, processo de realização, formação de ideias, suposição de hipóteses, reunião de informações, definição de dificuldades, identificação de elementos, busca de soluçôes, modificação do que é preciso, aperfeiçoamento do que é necessário, transformação da realidade, integralização de sentimentos e pensamentos, integração de ideias e realizaçôes, planejamento e execução de projetos. Além disso, problematizações, orientação, climatização, estimulação e valorização marcaram também o modo de como o processo de criatividade ocorre.

Estudar a criatividade a partir da perspectiva global do produto criativo nos permite conhecer os critérios que determinam que se um objeto, uma ideia ou uma obra são considerados criativos (SOLAR RODRÍGUEZ, 1999). Um dos critérios de valoração do produto é a originalidade, ou seja, seu caráter único e ímpar. Outros critérios utilizados são a satisfação e funcionalidade individual e/ou coletiva do produto.

Podemos entender também que o produto pode se materializar de distintas maneiras, como uma descoberta científica, uma invenção tecnológica ou uma manifestação artística, que conforme Menchén Bellón (2006, p. 235): "Un producto se puede desarrollar en el terreno de las artes, las ciencias, la 
técnica, las relaciones humanas; es decir, en todas las actividades que realiza el ser humano."

Quanto as perspectivas com foco no produto, considerando os autores especificados no quadro 1, percebemos que entendem o produto criativo quanto a sua originalidade por se referirem a esse resultado final como: algo novo, nova ordem sobre o entorno, resultados que eram desconhecidos, propriedades e qualidades novas, novas técnicas, novos esquemas, novos sistemas, diferentes experiências, distintos modos de enfocar a realidade, introdução de novidades, conversão de elementos conhecidos em outros, promoção de alternativas, provocação de mudanças no campo existente, algo inesperado. Compreendem o produto criativo também quanto a utilidade ao se referirem ao produto como algo detentor de valor e vitalidade. Dentre estes autores também encontramos referências as formas e aos estilos de expressão do produto criativo, como a literatura, a dança, a música, as artes cênicas, as artes plásticas, dentre outros. Um produto criativo pode ter impacto mundial como também pode ter alcance local e/ou alcance pessoal (MARÍN IBÁÑEZ, 2003). O importante é que de alguma maneira ele supra as necessidades do contexto e dos envolvidos.

As definições de criatividade com foco nas condições e no ambiente criativo consideram os contextos sociais, culturais, inter-relacionais, econômicos, históricos, ecoformativos dentre outros e estes influenciam no desenvolvimento da criatividade, seja auxiliando ou dificultando o processo (SOLAR RODRÍGUEZ, 1999). Assim, se percebe a importância de um clima favorável, de motivaçóes, de um ambiente cooperativo e aberto a comunicação (MOREJÓN, 2006).

Ao pensar na criatividade com foco na condição/ambiente, conforme os estudos dos pesquisadores citados no quadro 1, encontramos referências a influência exercida por: fatores ambientais; fenômenos e situaçóes sociais e culturais; sensibilidade a problemas, deficiências e lacunas; preocupação com melhoria e qualidade de vida das pessoas para atender as necessidades de um contexto; transformação do meio; condições oferecidas por famílias, escolas, empresas, comunidades e mundo. Assim, a ideia de condiçóes/ambientes criativos esteve relacionada as circunstâncias, sejam fatos, materiais ou pessoas, ou seja, marcadas pela existência de motivaçóes, de uma atmosfera que valoriza o pensamento inventivo e de clima que propicie liberdade e responsabilidade com o processo.

Ao tratar da criatividade com foco na pessoa/personalidade há que considerar as dimensóes cognitivas, metacognitivas, afetivas, biológicas, psicológicas e subjetivas, bem como suas interfaces com as bases históricas, 
sociais e culturais. Dessa forma, a pessoa é vista como um ator principal da criação (SOLAR RODRÍGUEZ, 1999; ROSMAN, 2006). De tal modo, com o foco na pessoa e na personalidade criativa foi possível identificar nas definiçóes dos autores citados no quadro 1, aspectos, como: aptidão, capacidade, técnica do pensamento, atitude, potencial, traço de personalidade, conflito inconsciente, disposição para criar, conduta, energia psíquica, atividade mental, imaginação poderosa, consciência, energia. Defendeu-se a ideia de uma personalidade aberta e flexível e com maturidade pessoal. Apresentaram relação com aspectos cognitivos e com a subjetividade humana. Associaram também tal enfoque com: curiosidade, interesse, sensibilidade, empenho, generosidade, valores e motivação intrínseca.

Identificamos nas definiçóes de criatividade analisadas vinculação com as cinco perspectivas globais, algumas apresentaram vinculação com um enfoque e outras definiçóes articulam mais de uma perspectiva como podemos observar no gráfico 2 .

Gráfico 2: Definições de criatividade e suas perspectivas
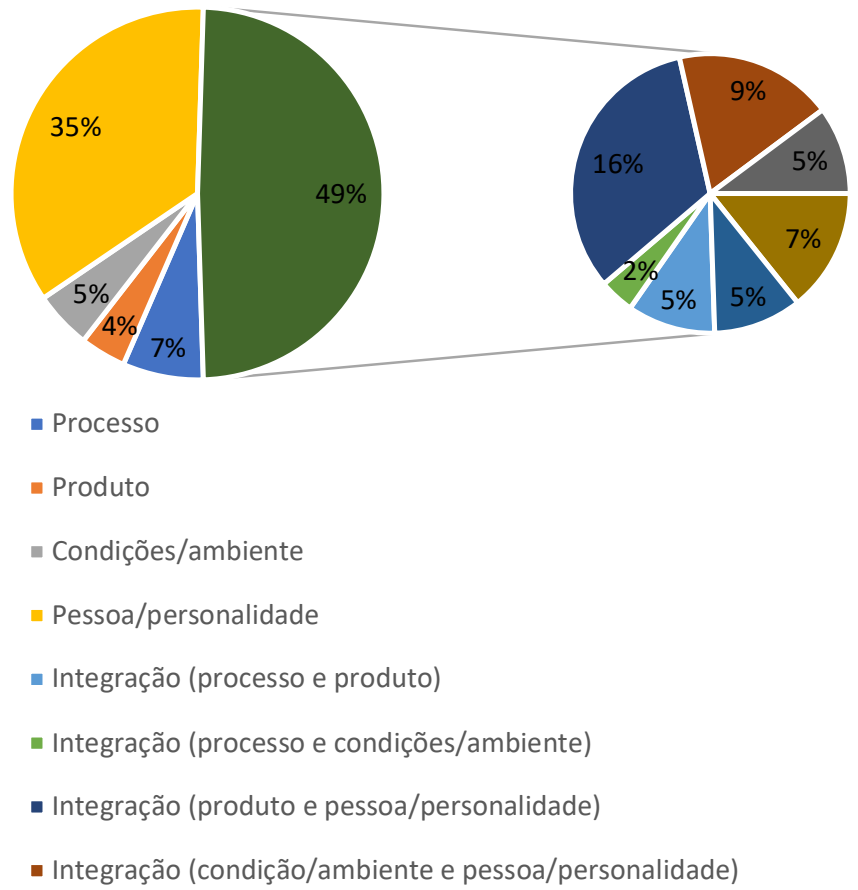

Fonte: Tavares e Suanno, 2020. 
Dentre as definiçóes analisadas $7 \%$ tiveram foco no processo criativo; $4 \%$ foco no produto criativo; $5 \%$ foco na condição/ambiente criativo; $35 \%$ com foco na pessoa/personalidade; e $49 \%$ apresentaram de alguma forma uma integração.

Observando especificamente as concepçóes que de alguma forma apresentaram algum tipo de articulação e integração entre um elemento e outro temos que por volta de $5 \%$ das concepçóes integraram quesitos relacionados ao processo e ao produto; em aproximados $2 \%$ integraram aspectos do processo e condição/ambiente; aproximadamente 16\% integraram aspectos da ideia de produto e pessoa/personalidade; em torno de $9 \%$ integrou-se aspectos de condição/ambiente e pessoa/personalidade; cerca de $5 \%$ se constituiu em integração ao enfocar no processo, produto e condição/ambiente; próximos a $7 \%$ integrou aspectos de produto, condição/ambiente e pessoa/personalidade e, por fim, em média 5\% percebemos a reunião de especificidades das quatro perspectivas - processo, produto, condição/ambiente e pessoa/personalidade.

Pensar a criatividade a partir da integração de perspectivas e enfoques, apresenta-se como um esforço recente e que ainda se encontra em processo de construção. Nesse sentido, ao percebermos os resultados gerados e as análises construídas, de certa maneira, nos surpreendemos e encontrarmos indícios de definiçóes de criatividade com integração de perspectivas em abordagens que se complexificam.

Como não há uma unicidade na compreensão da criatividade e nossa pesquisa aponta um indício de que as pesquisas e publicaçôes nesta área não estão estáticas e nem estagnadas, seguem pujantes. Ao mesmo tempo vislumbrarmos por identificar conceitos de criatividade que sejam fruto de esforços integradores e complexo;

No quadro 2 apresentamos uma organização da relação entre os autores das definiçôes analisadas e as perspectivas expressas.

Quadro 2: Autores das definiçóes analisadas e perspectivas expressas.

\begin{tabular}{|l|l|}
\hline Enfoque & Autor \\
\hline Processo & $\begin{array}{l}\text { Medinick (1980); Benning (1996); Torrance (1976); } \\
\text { Marín Ibánez (1980) }\end{array}$ \\
\hline Produto & Gutman (1967); Moraes (2006); Marín Ibánez (1980) \\
\hline \multirow{2}{*}{ Condiçáo/ambiente } & Alencar e Flith (2003); Motos (1990); Marín Ibánez \\
& $(1980)$ \\
\hline & Aznar (1974); De Bono (1986); Dudek (1993); Freud \\
& $(1958) ;$ Fromm (1982); Sillamy (1973); Runco (1996, \\
& 2007); Sternberg (1976); Rosman (2006); Menchen \\
& $(1991,2011,2012) ;$ Dittrich (2010); Kaufman (2006); \\
\hline
\end{tabular}




\begin{tabular}{|l|l|}
\hline & $\begin{array}{l}\text { Herrán Gascón (2003); Tindó (2009); Mitjáns } \\
\text { Martínez (1997); Marín Ibánez (1980) }\end{array}$ \\
\hline $\begin{array}{l}\text { Integraçáo } \\
\text { (processo e produto) }\end{array}$ & Murray (1982); Thurstone (1968) \\
\hline $\begin{array}{l}\text { Integraçáo } \\
\text { (processo, condição/ambiente e pessoa) }\end{array}$ & Suanno (2013) \\
\hline $\begin{array}{l}\text { Integraçáo } \\
\text { (produto e pessoa/personalidade) }\end{array}$ & $\begin{array}{l}\text { Barron (1976); Gervilha (1986); Prado Díez (1986); } \\
\text { Osborn (1971); Parnes (1962); Fernández Huerta }\end{array}$ \\
\hline $\begin{array}{l}\text { Integraçáo } \\
\text { (condiçáo/ambiente e } \\
\text { pessoa/personalidade) }\end{array}$ & $\begin{array}{l}\text { May (1979); Ambile (1985); Betancourt (1992, 1993); } \\
\text { Weschler (2011) }\end{array}$ \\
\hline $\begin{array}{l}\text { Integraçáo } \\
\text { (processo, produto e condiçáo/ambiente) }\end{array}$ & Stein (1967); Dabdoub (2005) \\
\hline $\begin{array}{l}\text { Integraçáo } \\
\text { (produto, condição/ambiente e } \\
\text { pessoa/personalidade) }\end{array}$ & $\begin{array}{l}\text { Rogers (1959); Brunner (2008); Csikszentmihalyi } \\
\text { (1988) }\end{array}$ \\
\hline $\begin{array}{l}\text { Integraçáo } \\
\text { (processo, produto, condição/ambiente e } \\
\text { pessoa/personalidade }\end{array}$ & González Quintián (2006); Torre (2003, 2008) \\
\hline
\end{tabular}

Fonte: Tavares e Suanno, 2020.

As definições de criatividade guardam em si aproximaçóes e distanciamentos e, neste estudo nos interessa identificar e compreender os esforços integradores por estes ampliarem a complexidade na compreensão do fenômeno e por objetivarem pensar a criatividade em perspectiva multidimensional, transdisciplinar e complexa. Um fenômeno que integra distintas dimensóes (RIBEIRO; MORAES, 2014) que se interacionam, de tal modo os autores assumem o desafio de uma aventura pela práxis inventiva que guarda incertezas.

A partir disso, podemos visualizar no quadro 2 autores que concebem a criatividade com foco em mais de um aspecto e promovem a conjugação entre: processo e produto; processo, condição/ambiente e pessoa; produto e pessoa/personalidade; condição/ambiente e pessoa/personalidade; processo, produto e condição/ambiente; produto, condição/ambiente e pessoa/personalidade; processo, produto, condição/ambiente e pessoa/personalidade

Atribuiremos destaque nesta publicação para as definiçóes de González Quintián (2006) e Torre $(2003$, 2008) que concebem a criatividade como integração entre processo, produto, condição/ambiente e pessoa/personalidade. Os referidos autores percebem a criatividade como uma dimensão humana transformadora do ser (pessoa/personalidade), transformadora também do meio (condição/ambiente), consubstanciado em 
produtos que sejam dinâmicos e fundamentais. Além disso, trata-se de um processo ao expressar o modo como ocorre a criatividade, sendo um "processo integrado de sentimento e pensamento, de ideias e realizaçóes” (GONZÁLEZ QUINTIÁN, 2008 apud TORRE, 2008, p. 274). Assim, a criatividade é considerada como um "potencial humano para gerar novas ideias dentro de um contexto de valores” (TORRE, 2008, p. 273), ou seja, uma interaçáo psicossocial vinculando-a a um bem social.

Violant (2006) afirma que as perspectivas citadas anteriormente se caracterizam como as principais vertentes no estudo da criatividade e que a integração destas precisa ser mais explorada, ampliadas e complexificadas, uma vez que a criatividade é um fenômeno complexo.

\section{Consideraçóes finais}

A pluralidade de definiçóes e de conceitos de criatividade pode se configurar como um elemento dificultador para a compreensão dele, no entanto a nitidez quanto as concepçóes e as epistemologias que os fundamentam podem contribuir para explicitar alguns aspectos. A pluralidade guarda em si oportunidades, desafios e contradiçóes, o que é uma riqueza a ser explorada.

Analisar nas definiçóes de criatividade as abordagens quanto ao produto criativo, processo criativo, condição e/ou ambiente criativo, pessoa e/ou personalidade criativa e a perspectiva que visa integrar as anteriores nos permitiu um panorama, identificar aspectos a serem aprofundados em futuras pesquisas bem como reafirmar que a criatividade é própria do humano e pode ser desenvolvida, assim como compor projetos de ensino, formação humana e formação profissional.

\section{Referências}

ALENCAR, Eunice M. L. Soriano de. El proceso crativo: mecanismos subyacentes. In: TORRE, Saturnino de la; VIOLANT, Verónica (Orgs.). Comprender y evaluar la creatividad: un recurso para mejorar la calidad de la enseñanza. Málaga: Ediciones Aljibe, 2006, v. 1, p. 191-196.

MARÍN IBÁÑEZ, Ricardo. Definición de la creatividad. In: MARÍN IBÁÑEZ, Ricardo; TORRE, Saturnino de la (Orgs.). Manual de la 
creatividad: aplicaciones educativas. $1^{a}$ ed. Barcelona: Vicens Vives, 2003. p. 95-99.

MENCHÉN BELLÓN, Francisco. El producto creativo: una revisión histórica. In: TORRE, Saturnino de la; VIOLANT, Verónica (Orgs.). Comprender y evaluar la creatividad: un recurso para mejorar la calidad de la enseñanza. Málaga: Ediciones Aljibe, 2006, v. 1, p. 229-238.

MITJÁNS MARTÍNEZ, Albertina. Criatividade, personalidade e educação. Tradução de Mayra Pinto. Campinas: Papirus, 1997.

MOREJÓN, Julián Betancourt. El entorno creativo: condiciones necessárias e indispensables para propiciar una atmosfera creativa. In: TORRE, Saturnino de la; VIOLANT, Verónica (Orgs.). Comprender y evaluar la creatividad: un recurso para mejorar la calidad de la enseñanza. Málaga: Ediciones Aljibe, 2006, v. 1, p. 197-204.

MORIN, Edgar; CIURANA, Emilio-Roger; MOTTA, Raúl Domingo. O método: estratégias para o conhecimento e a ação num caminho que se pensa. In: MORIN, Edgar; CIURANA, Emilio-Roger; MOTTA, Raúl Domingo. Educar na era planetária: o pensamento complexo como método de aprendizagem no erro e na incerteza humana. Tradução: Sandra Trabucco Valenzuela. 2a ed. São Paulo: Cortez, 2007. p. 15-40.

MORIN, Edgar. A máquina hipercomplexa. In: MORIN, Edgar. O método 3: o conhecimento do conhecimento. Tradução: Juremir Machado da Silva. 2. ed. ed. Porto Alegre: Sulina, 1999. p. 96-128.

MORIN, Edgar. A cabeça bem-feita: repensar a reforma, reformar o pensamento. Tradução: Eloá Jocobina. $9^{a}$ ed. Rio de Janeiro: Bertrand Brasil, 2004.

PRADO DÍEZ, David de. Activadores e inhibidores de la creatividad: múltiples bloqueadores, desbloqueadores y estimuladores de la creatividad. In: TORRE, Saturnino de la; VIOLANT, Verónica (Orgs.). Comprender y evaluar la creatividad: un recurso para mejorar la calidad de la enseńanza. Málaga: Ediciones Aljibe, 2006, v. 1, p. 215-227.

RIBEIRO, Olzeni Costa; MORAES, Maria Cândida. Criatividade em uma perspectiva transdisciplinar: rompendo crenças, mitos e concepçóes. Brasília: Liber Livro, 2014.

ROSMAN, Juan Carlos. El hombre creador. In: TORRE, Saturnino de la; VIOLANT, Verónica (Orgs.). Comprender y evaluar la creatividad: un recurso 
para mejorar la calidad de la enseñanza. Málaga: Ediciones Aljibe, 2006, v. 1, p. 177-189.

SOLAR RODRÍGUEZ, María Inéz. Qué se entiende por creatividad? In: SOLAR RODRÍGUEZ, María Inéz. Creatividad en educacion. $1^{\text {a }}$ ed. Penco: Impresos Hurtado, 1999.

SUANNO, João Henrique. Escola criativa e práticas pedagógicas transdisciplinares e ecoformadoras. 2013. 272 f. Tese (Doutorado em Educação) - Universidade Católica de Brasília, Brasília, 2013.

TORRE, Saturnino de la. Conceito de Criatividade. In: TORRE, Saturnino de la. Criatividade aplicada: recursos para uma formação criativa. Tradução: Carmen Carballal. São Paulo: Madras, 2008. p. 271-276.

VIOLANT, Verónica. Indicadores clásicos en la evaluación de la creatividad. In: TORRE, Saturnino de la; VIOLANT, Verónica (Orgs.). Comprender y evaluar la creatividad: un recurso para mejorar la calidad de la enseñanza. Málaga: Ediciones Aljibe, 2006, v. 2, p. 169-179.

Recebido em: 02 set. 2020

Aceito em: 10 dez. 2020 